Brewster Angle Polarizing Beamsplitter Laser Damage Competition: "P" polarization

C. J. Stolz, J. Runkel

November 14, 2012

SPIE Laser Damage Conference Boulder, CO, United States September 23, 2012 through September 26, 2012 
This document was prepared as an account of work sponsored by an agency of the United States government. Neither the United States government nor Lawrence Livermore National Security, LLC, nor any of their employees makes any warranty, expressed or implied, or assumes any legal liability or responsibility for the accuracy, completeness, or usefulness of any information, apparatus, product, or process disclosed, or represents that its use would not infringe privately owned rights. Reference herein to any specific commercial product, process, or service by trade name, trademark, manufacturer, or otherwise does not necessarily constitute or imply its endorsement, recommendation, or favoring by the United States government or Lawrence Livermore National Security, LLC. The views and opinions of authors expressed herein do not necessarily state or reflect those of the United States government or Lawrence Livermore National Security, LLC, and shall not be used for advertising or product endorsement purposes. 


\title{
Brewster Angle Polarizing Beamsplitter Laser Damage Competition: "P" polarization
}

\author{
Christopher J. Stolz \\ Lawrence Livermore National Laboratory, \\ 7000 East Avenue, L-491, Livermore, CA 94550 USA \\ Jeff Runkel \\ Quantel USA \\ 601 Haggerty Lane, Bozeman, MT 59715 USA
}

\begin{abstract}
Brewster angle plate polarizing beamsplitters play a critical role in splitting and combining beams within high power laser systems. A laser damage competition of polarizer beamsplitter coatings creates the opportunity to survey the current laser resistance these coatings within private industry, governmental institutions, and universities by a direct comparison of samples tested under identical conditions. The requirements of the coatings are a minimum transmission of $95 \%$ at "P" polarization and minimum reflection of $99 \%$ at "S" polarization at $1064 \mathrm{~nm}$ and 56.4 degrees angle of incidence. The choice of coating materials, design, and deposition method were left to the participant. Laser damage testing was performed according to the ISO 11254 standard utilizing a $1064 \mathrm{~nm}$ wavelength laser with a $10 \mathrm{~ns}$ pulse length operating at a repetition rate of $20 \mathrm{~Hz}$. A double blind test assured sample and submitter anonymity so only a summary of the results are presented. In addition to the laser resistance results, details of cleaning methods, deposition processes, coating materials and layer count, and spectral results are also shared. Because of the large number of samples that were submitted, damage testing was conducted at "P" polarization only with "S" polarization damage testing reserved for next year on these submitted samples. Also the samples were only tested in the forward propagating direction; specifically samples were irradiated from air as the incident medium, through the thin film, and then through the substrate. In summary, a 6:1 difference existed for "P" polarization damage fluences amongst all of the competitors with the dominate variables that impacted the laser resistance being the deposition materials, deposition process, and cleaning method.
\end{abstract}

Keywords: damage testing, polarizer, thin film, Brewster angle, multilayer, $1064 \mathrm{~nm}$ laser, nanosecond pulse length, and ISO21254-2

\section{INTRODUCTION}

This latest thin film laser damage competition represents the fifth in a series of damage competitions started in 2008 at the Boulder Damage Symposium. To date, a large range of coating types have been tested including a $1064 \mathrm{~nm}$ normal incident high reflector ${ }^{1}$ tested with $5 \mathrm{~ns}$ pulses, a $786 \mathrm{~nm}$ femtosecond $(200 \mathrm{fs})$ normal incident high reflector $^{2}$, a $351 \mathrm{~nm}$ antireflection coating ${ }^{3}$ tested with $7.5 \mathrm{~ns}$ pulses, a $193 \mathrm{~nm}$ excimer mirror ${ }^{4}$ tested with $13 \mathrm{~ns}$ pulses, and finally this year's competition of a Brewster angle $1064 \mathrm{~nm}$ polarizer. In each competition, it was observed that a wide range of laser resistance exists between the lowest and highest laser resistant samples with the largest range being over $100 \times$ for the $1064 \mathrm{~nm}$ nanosecond mirrors. Although this is not a formal study isolating a single variable to test a hypothesis, general trends can be observed in this competition between thin film variables and the range of capability within the coating industry in manufacturing high resistance polarizers.

\section{PARTICIPATION}

Twenty-six samples were submitted this year from seventeen different participants who represented six different countries. A list of the participants, their respective countries, and number of years of participation in this series of thin film laser damage competitions are listed in table 1. The participating countries and number of samples were: 
China (9), Germany (8), USA (4), United Kingdom (3), Japan (1), and Switzerland (1). This was the first year that participants from the United States were in the minority of participating countries.

Table 1 List of participating companies or institutes for the BDS than film damage competition

\begin{tabular}{|l|c|c|}
\hline Company / Institute & Country & Years of participation \\
\hline Changchuan Institute of Optics & China & 1 \\
\hline CVI Melles Griot & USA & 1 \\
\hline CVI Melles Griot & UK & 1 \\
\hline Hardin Optical Company & USA & 1 \\
\hline Laser Components GmbH & Germany & 3 \\
\hline Laser Zentrum Hannover & Germany & 5 \\
\hline Laserhof Frielingen GmbH & Germany & 2 \\
\hline Laseroptik GmbH & Germany & 1 \\
\hline Okamoto Optics & Japan & 2 \\
\hline Optimax Systems & USA & 1 \\
\hline Opturn Company Ltd & China & 1 \\
\hline Sandia National Lab (NM) & USA & 1 \\
\hline SCHOTT & Switzerland & 1 \\
\hline Shanghai Institute of Optics and Fine Mechanics & China & 4 \\
\hline Sichuan Corder Technology Inc. & China & 1 \\
\hline SLS Optics & UK & 2 \\
\hline Tonjgi University & China & 1 \\
\hline
\end{tabular}

\section{SAMPLES}

The coated samples had a spectral requirement of $>95 \%$ transmission at "P" polarization and $>99 \%$ reflection at "S" polarization at $1064 \mathrm{~nm}$ at 56.4 degrees (Brewster's angle). Environmental requirements were ambient lab conditions (40\% relative humidity and 20 degrees Celsius). Participants supplied $50 \mathrm{~mm}$ diameter substrates that were $10 \mathrm{~mm}$ thick in either fused silica or BK7. No significant correlation between substrate material and damage threshold was observed. Participants each provided a spectral plot as shown in figure 1, to validate spectral performance. Participants also provided a description of the coating deposition process, coating materials, layer count, and cleaning method.

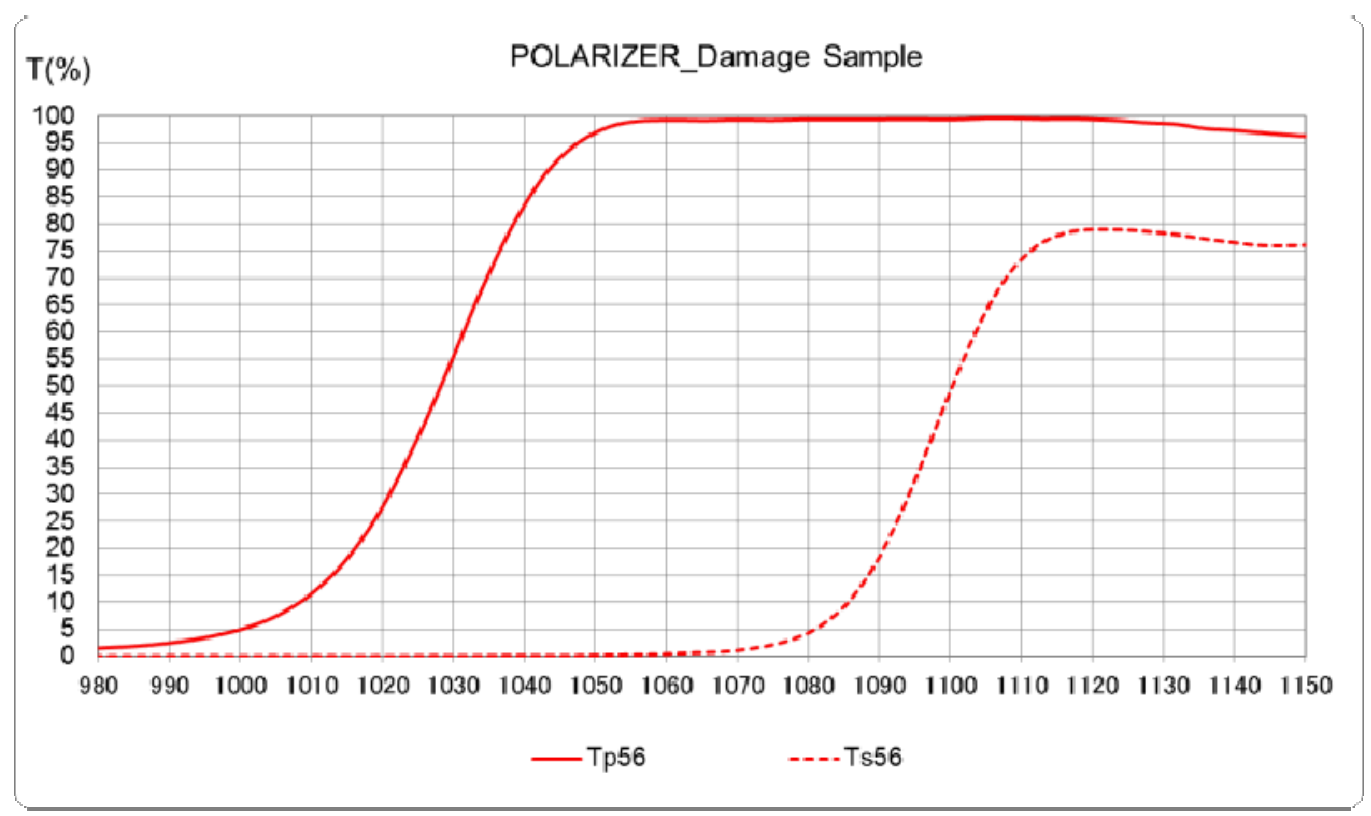

Fig. 1 Representative spectral characteristics of the contributed samples. 
Samples were assigned a unique two digit participant code to maintain sample anonymity. The first digit consisted of a letter ranging from $\mathrm{A}$ to $\mathrm{R}$ for the seventeen participants. The second digit was a sample number consisting of a 1 or 2 depending on how many samples were supplied by the participant. The identity of the suppliers and participant code was only known by an administrative assistant to maintain a double blind experiment. The author and damage testing service only had access to the participant code so as to remain unbiased and to protect the identities of participants whose samples had lower laser resistance.

All of the spectral plots indicate that a long wave pass design strategy was employed by each participant. When designing polarizer coatings, a series of compromises and optimizations must be made. Spectrally, polarizers are tilted coatings that can be designed as either a short wave pass or long wave pass. ${ }^{5}$ These different design strategies impact the polarizing spectral bandwidth, extinction ratio, design complexity, overall film thickness, and electric field profile. ${ }^{6-9}$ The long wave pass design is most common because it yields a wider polarizer spectral bandwidth and thinner coating, but it does have an unfavorable electric field profile in both "P" and "S" polarization.

Three different deposition processes, e-beam, ion beam sputtering, and ion assisted deposition, were used to manufacture the samples for this composition. Four different high index coating ma terials, $\mathrm{HfO}_{2}, \mathrm{Ta}_{2} \mathrm{O}_{5}, \mathrm{ZrO}_{2}$, and a mixture of $\mathrm{HfO}_{2} \& \mathrm{Al}_{2} \mathrm{O}_{3}$, were used. Histograms of the deposition processes and coating materials are shown in figures 2 and 3. The most common deposition process used to manufacture the samples was electron beam deposition. Within the IBS sample population, a few of them were rugate films (either discrete or continuous). These will be identified in the damage threshold plots discussed in section 5. $\mathrm{SiO}_{2}$ was the low index material used in all of the samples. $\mathrm{HfO}_{2}$ is the standard high index material choice for high laser resistance at $1064 \mathrm{~nm}$ which is reflected in more than half of the submitted samples being manufactured with this material. However, this material has a lower refractive index than $\mathrm{Ta}_{2} \mathrm{O}_{5}$ or $\mathrm{ZrO}_{2}$ which results in a lower polarizing spectral bandwidth. $\mathrm{HfO}_{2}$ also tends to be polycrystalline leading to higher scatter than $\mathrm{Ta}_{2} \mathrm{O}_{5}$ which tends to make very low scattering amorphous films. The lower refractive index and scattering drawbacks for $\mathrm{HfO}_{2}$ motivate interest in alternate high index coating materials.

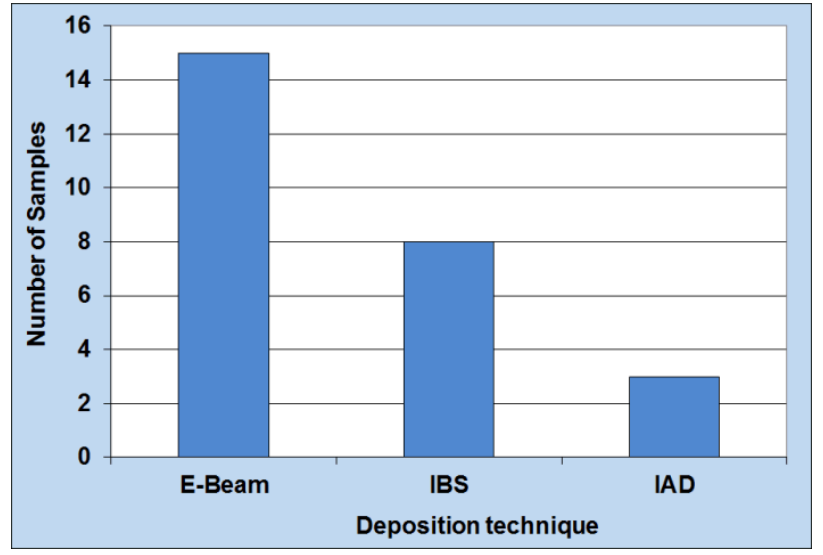

Fig. 2 Coating deposition process histogram.

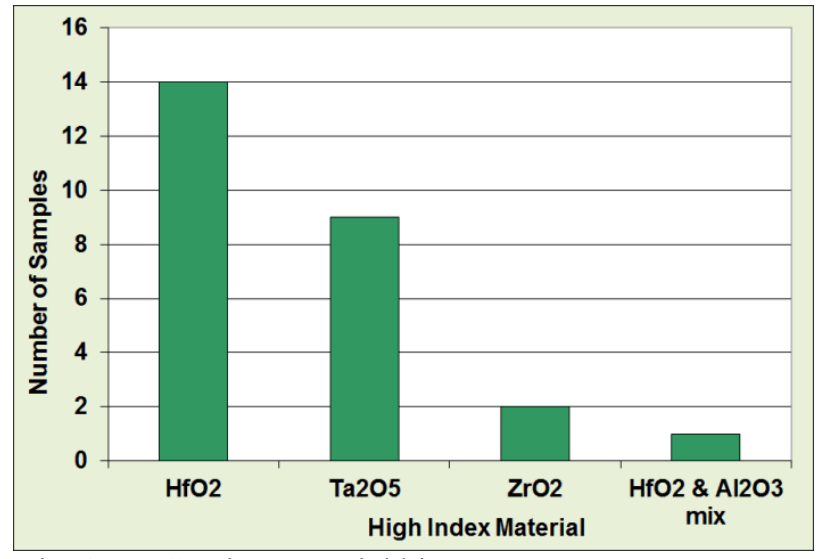

Fig. 3 Coating material histogram.

\section{DAMAGE TESTING}

The LIDT measurements where performed at Quantel USA according to ISO 11254-2 ${ }^{10}$. An illustration of the setup is in figure 4. The test laser operates at a wavelength on $1064 \mathrm{~nm}$ with a $10 \mathrm{~ns}$ pulse length and repetition rate of 20 Hz. The beam diameter was $0.53 \mathrm{~mm}$ at the sample plane in $\mathrm{TEM}_{00}$ mode. The tests were conducted at 56.4 degrees incidence angle at "P" polarization. The samples were tested in the forward propagating direction only, specifically the laser direction went from air, through the film, and then into the substrate.

100 sites were tested on each sample with 200 shots per site. Laser damage was determined by optical microscope inspection of the irradiated area of the sample at $20 \times$ magnification. The damage threshold was determined by the damage frequency method. Damage probability statistics were gathered as illustrated in figure 5. A least squares linear fit of the data was calculated to determine the zero percent failure intercept. A full description of the damage set up and testing method are described in detail on the Quantel website. ${ }^{11}$ 


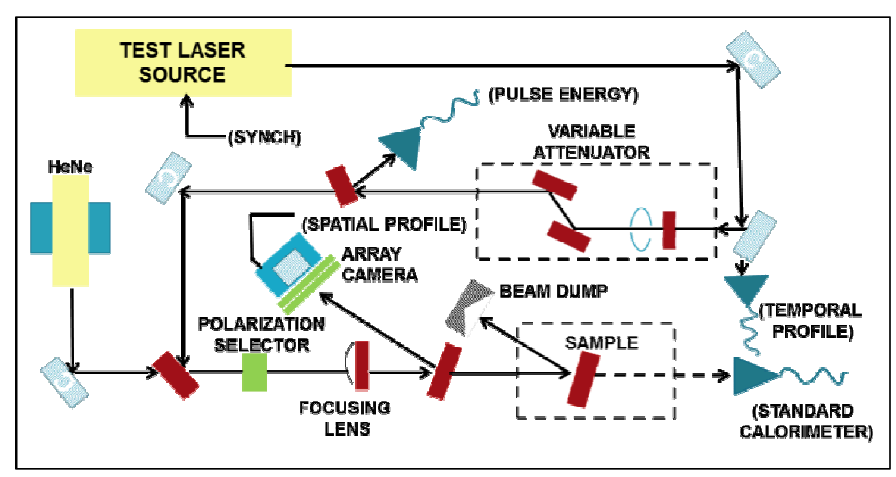

Fig. 4 Laser damage test setup.

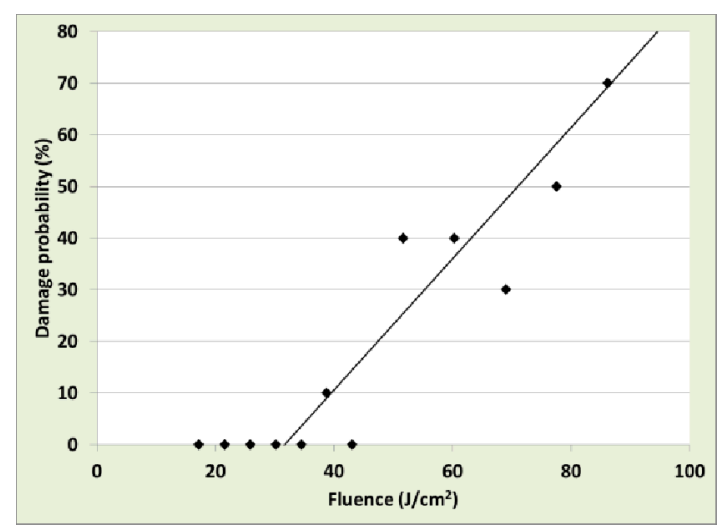

Fig. 5 Damage threshold probability results for the highest laser resistant sample.

\section{RESULTS}

A summary of the damage threshold results are shown in figures 6 and 7. The coatings deposited by electron beam tended to have the highest laser resistance. Of the electron-beam deposition films, the highest laser resistant high index material was $\mathrm{HfO}_{2} . \mathrm{Ta}_{2} \mathrm{O}_{5}$ coatings tended to have higher laser resistance for the densified coating processes, IAD and IBS. What is particularly interesting is that the highest laser resistant coatings from each deposition process were cleaned using ultrasonics and the lower laser resistant coatings tended to be cleaned manually. For the densified coating processes, the highest laser resistant coatings were also dry etched before coating deposition by either plasma or ion sources. A similar trend was observed in the first damage competition where the highest damage threshold $1064 \mathrm{~nm}$ high reflector coating was dry etched before deposition.

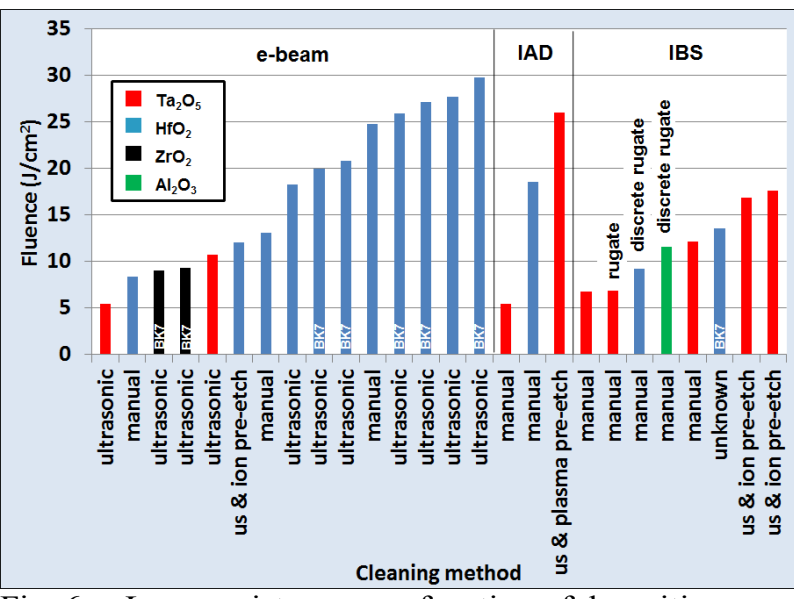

Fig. 6 Laser resistance as a function of deposition process, coating material, and cleaning method (us $=$ ultrasonic) .

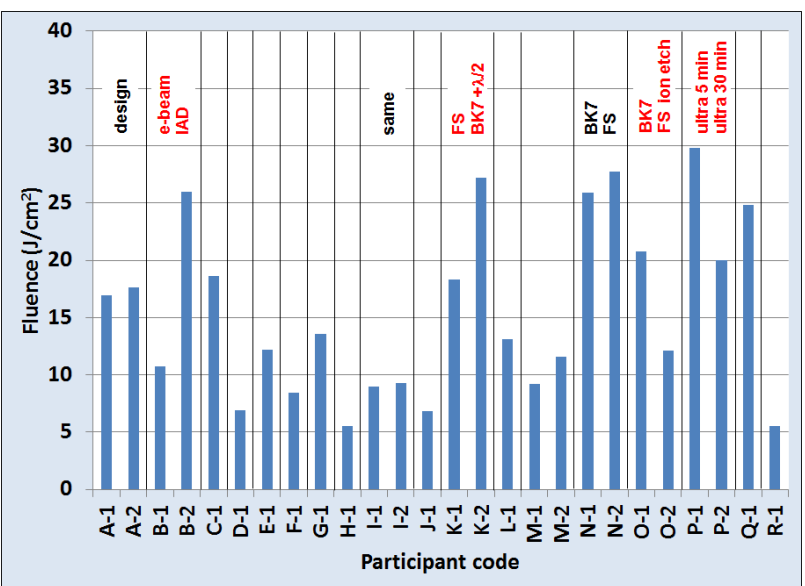

Fig. 7 Laser resistance by participant (ultra $=$ ultrasonic).

The rugate designs deposited by ion beam deposition did not show a significant advantage from a laser resistan ce perspective. The $\mathrm{Al}_{2} \mathrm{O}_{3}$ mixture with $\mathrm{HfO}_{2}$ was the most laser resistant of the rugate coatings. Some of the coating participants provided two samples and described the differences between the coatings creating an opportunity to observe trends with minimal variables. Similar laser resistance was observed with differing designs (participant A), identical deposition conditions (participant I), and for a coating deposited on substrates of different material composition, BK7 versus fused silica (participant N). Where there were significant observed differences in laser resistance between different samples supplied by the same participant a significantly higher laser resistance for an IAD coating over e-beam coating was observed for participant B. For participant $\mathrm{K}$ they changed the substrate material and added a thicker overcoat to one of the coatings. In this case the thicker overcoat deposited on BK7 had 
a higher laser resistance than the thinner overcoat deposited on fused silica. For participant $\mathrm{O}$, two variables were also changed. The coating on the BK7 substrate had a higher laser resistance than the coating deposited on a fused silica substrate which was also ion etched before deposition. Finally, participant $\mathrm{P}$ showed that samples cleaned for only 5 minutes with ultrasonics performed better than substrates that were cleaned with ultrasonics for 30 minutes.

In order to observe potential trends with substrate material, BK7 substrates are indicated in figure 6. The remaining substrates were fused silica. There does not appear to be a significant dependence of substrate material and laser resistance of the coated sample. No significant trends were observed between laser resistance and the number of coating layers. In the first damage competition of the $1064 \mathrm{~nm}$ high reflector coatings, it was possible to determine if overcoats were used in the coating design by either an even or odd number of layers and the impact of the overcoats in the laser resistance of the coating. Polarizer coatings tend to be highly optimized designs so it is impossible to determine the use of an overcoat by whether the number of layers is odd or even so unfortunately the only available overcoat information was the data provided by participant K. Overcoat thicknesses have been determined to have a significant impact on the laser resistance of Brewster angle plate polarizers at "S" polarization, however, this remains an unanswered question at "P" polarization. ${ }^{12}$

\section{CONCLUSIONS}

The range of laser resistance for these Brewster's angle thin film polarizers submitted to this competition and tested at "P" polarization is $6 \times$. The most significant variables that appeared to have a positive impact on the laser resistance of these coatings were deposition process (e-beam), coating material $\left(\mathrm{HfO}_{2}\right)$, ultrasonic cleaning, and dry etching of the substrate before deposition of the film. Next year the samples will be retested at "S" polarization which should lead to some interesting comparisons between polarization dependent laser resistance.

\section{AKNOWLEDGEMENTS}

The authors would like to acknowledge all of the participants who prepared the samples and provided the information about how the coatings were manufactured. These samples represent a significant investment to manufacture by the companies that participated. Quantel USA graciously donated all of the laser damage testing. Finally, Artika Lal organized the data and samples to maintain a double blind experiment.

This work performed under the auspices of the U.S. Department of Energy by Lawrence Livermore National Laboratory under Contract DE-AC52-07NA27344.

\section{REFERENCES}

1. Stolz, C. J., Thomas, M. D., and Griffin, A. J., "BDS thin film damage competition," in Laser-Induced Damage in Optical Materials: 2008, G. J. Exarhos, D. Ristau, M. J. Soileau, and C. J. Stolz, eds., Proc. SPIE 7132, 71320C-1-6 (2009).

2. Stolz, C. J., Ristau, D., Turowski, M., and Blaschke, H., "Thin film femtosecond laser damage competition," in LaserInduced Damage in Optical Materials: 2009, G. J. Exarhos, V. E. Gruzdev, D. Ristau, M. J. Soileau, and C. J. Stolz, eds., Proc. SPIE 7504, 75040S-1-6 (2010).

3. Stolz, C. J., Caputo, M., Griffin, A. J., and Thomas, M. D., "BDS thin film UV antireflection laser damage competition," in Laser-Induced Damage in Optical Materials: 2010, G. J. Exarhos, V. E. Gruzdev, J. A. Menapace, D. Ristau, and M. J. Soileau, eds., Proc. SPIE 7842, 784206-1-5 (2010).

4. Stolz, C. J., Blaschke, H., Jensen, L., Mädebach, H., and Ristau, D., "Excimer mirror thin film laser damage competition," in Laser-Induced Damage in Optical Materials: 2011, G. J. Exarhos, V. E. Gruzdev,J. A. Menapace, D. Ristau, and M. J. Soileau,, eds., Proc. SPIE 8190, 819007-1-8 (2011).

5. Macleod, H. A., "Tilted coatings," Chapter 8 in Thin-film optical filters, Taylor \& Francis Group, New York, New York, USA 2001.

6. Zhu, M., Yi, K., Fan, Z., Shao, J., "Theoretical and experimental research on spectral performance and laser-induced damage of Brewster's thin film polarizers,” Applied Surface Science 257, 6884-6888 (2011).

7. Chen, N. Wu, Y., Wang, Z., Ling, L., Xia, Z., Wu, H., and Lv, G., "The influence of micron-sized nodules on the electricfield distribution in thin-film polarizers," in Seventh International Conference on Thin Film Physics and Applications, J. Chu and Z. Wang eds., Proc. SPIE 7995, 79950Q-1-4 (2011).

8. Stolz, C.J., "Brewster's angle thin film plate polarizer design study from an electric field perspective," in Advances in Optical Interference Coatings, C. Amra and H. A. Macleod, eds, Proc. SPIE 3738, 347-353 (1999). 
9. Monga, J. C., "Multilayer thin-film polarizers with reduced electric-field intensity," J. of Modern Optics 36, 769-784 (1989).

10. ISO 11254-2: Lasers and laser-related equipment -- Test methods for laser-induced damage threshold -- Part 2: Threshold determination, Technical Committee: Optics and Optical Instruments, Subcommittee: Lasers and Laser-Related Equipment, International Standard 2001, Genève, Switzerland, International Organization for Standardization.

11. http://www.quantel-laser.com/tl files/client/LASER\%20DAMAGE\%20TESTING/QuantelDamage \%20Test $\% 20$ Descriptions.pdf

12. Stolz, C.J., Génin, F.Y., Reitter, T.A., Molau, N.E., Bevis, R.P., von Gunten, M.K., Smith, D.J., and Anzellotti, J.F., "Effect of $\mathrm{SiO}_{2}$ overcoat thickness on laser damage morphology of $\mathrm{HfO}_{2} / \mathrm{SiO}_{2}$ Brewster's angle polarizers at $1064 \mathrm{~nm}$," in LaserInduced Damage in Optical Materials: 1996, H.E. Bennett, A.H. Guenther, M.R. Kozlowski, B.E. Newnam, and M.J. Soileau, eds., Proc. SPIE 2966, 265-272 (1997). 